\title{
26 anos de REF: trouxemos as chaves?
}

\begin{abstract}
A produção de Bruna Macedo Goulart (2018), estudante de graduação em Letras, provocada pela professora que propôs às/aos suas/seus alunas/os que escrevessem sobre alguma situação traumática vivida na infância, após terem se detido no estudo do livro memorialístico Infância, de Graciliano Ramos (2013), leva-nos a refletir sobre as formas como crianças são socializadas, subjetivando-se em práticas que reproduzem e operam estereótipos binários de gênero que separam meninos e meninas.
\end{abstract}

A casa sem porta

Bruna Macedo Goulart

"A recordação de uma hora ou de alguns minutos longínquos não me faz supor que a minha cabeça fosse boa. Não. Era, tanto quanto posso imaginar, bastante ordinária. Creio que se tornou uma péssima cabeça. Mas daquela hora antiga, daqueles minutos, lembro-me perfeitamente."

Graciliano Ramos

Em tudo que sou hoje, resta um pouco do que um dia já fui. Tão pequena que poderia caber em qualquer colo que fosse, escalava as árvores, escondia-me nas frestas e corria descalça às ruas sem saída como se fosse chegar a algum lugar. Creche, um ambiente tão cheio de pessoas e descobertas. Exatamente ali que descobri toda a feiura do mundo e dos homens. O horror e o medo que não viriam dos contos de fadas lidos pelas professoras todos os dias. A ansiedade que afligia cada criança antes do intervalo para brincar no parque foi inútil naquela manhã, eu não imaginava que seria. Coloquei meus tênis com dificuldade, esfregando os olhos para que o sono fosse embora depois de um longo cochilo nos colchonetes azuis que povoavam o chão da sala.

Enfim abriram o portão do parque e surgiu um formigueiro de crianças que corria em todas as direções procurando sua brincadeira do dia. Com o olhar fixo, resolvi disparar para a casinha rosa do parque com minha amiga para cozinharmos

. Esta obra está sob licença Creative Commons. 
um bolinho de areia nas panelas de plástico. Reunimos todos os ingredientes que eram compostos por pequenas folhas, flores azuis e gravetos. Ouvi um estrondo forte abrir a porta da casinha e com ele uma invasão surgiu. Três meninos entraram, um deles fechava as janelas e mantinha a porta segura, 0 outro segurava minha amiga na parede com força enquanto o terceiro menino tentava beijá-la. Ela me pediu ajuda com o rosto retorcido em desespero e meu corpo todo estava paralisado. Nesse exato momento o menino que vigiava a porta tentou me segurar e então fugi pela janela, deixando meu cadarço preso. Caí no chão de areia e corri para o mais longe que pude, queria fugir daquele lugar e me sentir segura. Enfim encolhi-me e respirei, ofegante.

Experimentei ali, pela primeira vez, o sabor da covardia e do medo das coisas reais que assombram as mulheres durante qualquer momento da vida. Não sabia ainda, naquele tempo, que ser mulher é sempre olhar para trás quando se está sozinha durante a noite, é estar sempre preparada para correr para um lugar seguro. Naquela manhã me senti, sobretudo, covarde em deixá-la naquela casa na qual já não havia porta. Acompanhados, vieram o medo e a culpa fazer morada em mim.

Meninos e meninas nos tempos iniciais da infância em momentos de brincadeiras numa escola de educação infantil (pré-ensino fundamental) já (in)encorporados/as em ações que repetem e, pela repetição, constituem performatividades de gênero (BUTLER, 2003) que vulnerabilizam o feminino e constroem o que Robert Connell (1987) categorizou como masculinidade hegemônica, que se constitui na negação de tudo que é atribuído ao feminino. Padrão de masculinidade que também pesa sobre os homens, tanto para os que dele se afastam, como para os que procuram sustentá-lo (CONNELL; MESSERSCHMIDT, 2013). Mas a vulnerabilidade certamente resta para as mulheres e para todos/as que se aproximam dos padrões de feminilidade.

Por mais chocante ou inadequado que possa parecer, não estamos assistindo, nesse relato de um trauma infantil de menina encoberto na ação de brincar, ao ataque de um grupo de pequenos homens a duas pequenas mulheres colocadas em risco, imobilizada uma delas, em fuga a outra? Esta menina marcada para sempre pelo medo e pela culpa por ter deixado a amiga à mercê desses pequenos homens que queriam beijálas. E a outra menina, aquela que não fez sua narrativa, que ficou imobilizada por três meninos, numa casa sem porta? Com que relato nos falaria desta experiência vivida? Ou teria se protegido pelo recalcamento do doloroso, esquecendo-a?

Dar beijos, ou roubar beijos? Quando o beijo dado, um carinho, expressão de afeto, transforma-se em agressão, porque roubado sem o consentimento da pessoa, a que esta cena nos remete? Nas relações entre jovens e entre adultos falamos em assédios, em estupros (sem esquecermos que crianças são 
vítimas frequentes de agressões sexuais, e na grande parte das vezes em ambiente familiar). Estupros que, em geral, precedem os feminicídios. Retomando o relato de Bruna, "Experimentei ali, pela primeira vez, o sabor da covardia e do medo das coisas reais que assombram as mulheres durante qualquer momento da vida".

Articulamos o corajoso e instigante texto da jovem estudante de Letras com a afirmativa da pré-candidata à presidência pelo Partido Comunista do Brasil, Manuela D’Ávila, sobre a dificuldade de ser mulher no país, comentando sua participação em programa da TV Cultura (emissora pública do Estado de São Paulo), quando teve sua fala praticamente impedida pelas interrupções dos entrevistadores e das entrevistadoras. Manuela considerou o ambiente do programa como "violentamente hostil" e afirmou que "não é fácil ser mulher no Brasil", reportando-nos à narrativa de Bruna: "Não sabia ainda, naquele tempo, que ser mulher é sempre olhar para trás quando se está sozinha durante a noite (...)".

Reproduzimos aqui a narrativa de Bruna, pois nos remeteu a questões muito discutidas nestes 26 anos da revista, que foi construída como feminista e agora vivencia este cenário de retrocesso de direitos duramente conquistados e impedimento da luta por novos direitos, num clima de ódio e demonização de movimentos, organizações e pessoas. Mencionamos, além dos episódios que resultaram na retirada dos estudos de gênero e sexualidade de Planos de Educação no Brasil com a consequente perseguição a professores em todos os níveis de ensino, as recentes ameaças e agressões à pesquisadora Débora Diniz por sua luta pela descriminalização do aborto no país.

A narrativa da Bruna nos remete também ao incremento das violências contra as mulheres no Brasil nas últimas décadas, conforme demonstram informações recentes divulgadas amplamente pela mídia e por várias outras instituições. Dados do Banco Mundial mostram, por exemplo, que os assassinatos das mulheres das Regiões Norte e Nordeste aumentaram em $75,0 \%$ entre 2003 e 2013 , afetando principalmente as negras e indígenas. Ou seja, as mais pobres. Considerando-se as negras e pardas, no mesmo período, o aumento no Nordeste atingiu 103,0\% (GUKOVAS et al., 2016). Embora as mulheres das classes médias também sejam vítimas das violências físicas e psicológicas e da sua expressão extrema, o feminicídio, tais informações indicam as sérias implicações das intersecções entre gênero, raça e classe social: uma certa seletividade no exercício da violência, mais comumente exercida pelos parceiros e ex-parceiros. Dados sobre os anos posteriores revelam a tendência ao incremento do feminicídio. Por exemplo, o Atlas da Violência 2018 destaca que, em 2016, 4.645 mulheres foram mortas no país, atingindo-se uma taxa de 4,5 homicídios para cada 100 mil brasileiras. Violências que, não raro, atingem 
também, em escala crescente, as crianças e as pessoas mais jovens (CERQUEIRA et al., 2018).

Seguindo uma tradição de debates sobre a situação das mulheres, suas lutas, seus receios e desafios, neste último número de 2018, a seção Artigos reúne discussões teóricas e reflexões que resultam de estudos empíricos sobre variados temas atuais, de interesse do campo dos estudos feministas e de gênero. Os três primeiros artigos abordam o pensamento feminista de esquerda, em diferentes contextos e a partir de distintas preocupações teóricas e empíricas. O primeiro deles, intitulado Feminismo materialista na França: sócio-história de uma reflexão, elaborado por Maira Luisa Gonçalves Abreu, examina o contexto histórico e teórico que marcou a emergência do pensamento de representantes do feminismo materialista na França na década de 1970, destacando as contribuições de Christine Delphy, Colette Guillaumin, Nicole-Claude Mathieu e Monique Wittig; o segundo aborda a prostituição no pensamento marxista clássico e seu subtítulo contém a chave da interpretação adotada pela autora, Clarisse Goulart Paradis: A questão da prostituição no marxismo clássico: a crítica ao capitalismo e à dupla moral burguesa. A autora destaca o modo como as análises marxistas, elaboradas entre o século XIX e o início do século XX, refletem visões específicas sobre a autonomia sexual e a superação dos mecanismos de opressão das mulheres trabalhadoras; Rodrigo Otávio Moretti-Pires et al. assinam o terceiro artigo - Na esquina da esquerda: homofobia e os socialistas brasileiros em "O Lampião da Esquina" (19781981) -, focalizando o pensamento de esquerda sobre questões de gênero num famoso jornal brasileiro na década de 1970. Ou seja, na mesma década à qual se refere o primeiro artigo a respeito do pensamento feminista materialista francês. Após analisar as edições do jornal, os autores concluem que as demandas LGBT não foram contempladas pelo veículo em virtude da dificuldade de assimilação da sua dimensão política. No artigo seguinte, La adopción por parejas del mismo sexo en Colombia, una revisión desde el psicoanálisis, Jaime Carmona Parra e Isabel Cristina Posada analisam os resultados de uma revisão bibliográfica sobre conceitos centrais elaborados pela Psicanálise para uma compreensão da subjetividade e da sexualidade. Os manuais da Psiquiatria são questionados, bem como as noções de normal e patológico, entre outras, assinalando-se o caráter múltiplo do masculino e do feminino, da maternidade e da paternidade, interpretadas como construções simbólicas vinculadas ao desejo.

Explorando um tema ligado à maternidade e à paternidade, no artigo "Estará nas pílulas a solução?". O debate social sobre as pílulas anticoncepcionais em O Globo, 1960 1970, Tânia Maria Dias et al. sintetizam o debate sobre pílulas 
anticoncepcionais no Brasil, por meio da análise de matérias publicadas pelo jornal O Globo nas décadas de 1960 e 1970. As tensões entre diferentes atores - médicos, Igreja, autoridades públicas, entidades de planejamento familiar - são analisadas, destacando-se a entrada tardia do Estado no debate e nas ações, mediante o resgate da noção de "paternidade responsável" construída pela Igreja Católica.

Os dois artigos seguintes enfatizam ainda mais as perspectivas sócio-históricas, recuando mais no tempo. No primeiro deles, $O$ "direito" de falar em pleitos: o gênero nos códigos jurídicos afonsinos, numa abordagem que articula as contribuições da História Cultural do Direito Medieval e os Estudos de Gênero, Marcelo Pereira Lima examina a legislação do governo do Afonso X de Leão e Castela (1252-1284), refletindo sobre os vieses de gênero que orientaram as atividades, práticas e ofícios jurídicos ligados aos poderes do uso da palavra. No segundo, Encarcerada pelo homoerotismo: Clara Fernandes, uma lésbica perante o Tribunal da Inquisição, Ronaldo Manoel Silva focaliza um processo inquisitorial sobre a conduta de Clara Fernandes, uma jovem lésbica cuja sentença de sodomia foi promulgada em 1556, ou seja, num período em que o sexo entre mulheres era passível de morte na fogueira.

Obras clássicas da literatura internacional e nacional são tratadas nos três artigos subsequentes: explorando registros sobre relações de gênero no período clássico na Grécia, Christian Muleka Mwewa et al., no artigo Calipso e a intransigência do gênero, interpretam as implicações de gênero nas atitudes da personagem Calipso, do Canto 5 da obra Odisséia, poema épico atribuído a Homero, escrito aproximadamente no século VIII antes de Cristo; no artigo Cuerpos y espacio en un mito de origen alternativo, Nadia DerOhannesian dialoga com as especificidades do mito da origem da humanidade construído pela escritora britânica Doris Lessing, na obra The Cleft, destacando as críticas subjacentes à mitologia tradicional sobre homens e mulheres.

O artigo de Valeria Rosito - "Avisem-me se eu começar a me tornar eu mesma demais" - gênero em dupla valia na pena clariceana nos anos de chumbo - analisa crônicas escritas por Clarice Lispector, publicadas no Jornal do Brasil entre os anos 1960 e 1970, refletindo sobre as sutilezas do trânsito de sua escrita entre o ficcional e o não ficcional nas interações com o gênero.

A fotografia é objeto de reflexão de dois artigos, um deles elaborado por Sandra del Pilar López Dietz et al., intitulado Representación de la Mujer en la Prensa de Principios del Siglo XX en La Araucanía, Chile: el caso de la Revista Tic Tac, que ressalta o caráter hegemônico dos modelos socioculturais tradicionais impostos pelos grupos de poder durante o pósguerra na região; Maria Thereza Soares et al., no artigo Um 
Olhar sobre a fotografia feminista brasileira contemporânea, sintetizam o processo de inserção das mulheres nas artes visuais no Brasil, destacando as dimensões de gênero na produção de fotografias sobre o corpo, em particular no autorretrato, abordado como "instrumento de discurso".

O corpo volta a ser objeto de atenção nos artigos posteriores. Em Los estereotipos de género a partir de la desnudez y La cabellera femeninas: elementos para el fomento a La violencia simbólica, Carolina Serrano-Barquín et al. interpretam a nudez e a cabeleira feminina como características identitárias de gênero - estereotipadas e naturalizadas -, articuladas ao conceito de violência simbólica; no artigo Vivências e percepções de sexualidade de portuguesas com mais de 65 anos, as autoras Sara Queiroga, Sara Isabel Magalhães e Conceição Nogueira sintetizam os resultados de entrevistas individuais realizadas com mulheres idosas, analisando suas percepções sobre papéis de gênero, sexualidade e casamento, sondando as interferências do envelhecimento sobre suas condutas sexuais e conjugais.

Aspectos relevantes sobre a situação das mulheres em outros países também são ressaltados nos artigos seguintes. María Angélica Cruz Contreras elaborou o artigo Trayectorias políticas femeninas antes del Golpe de Estado en Valparaíso (Chile): articulando normas de género y memoria social a partir dos relatos de mulheres envolvidas com a militância de esquerda antes e depois do Golpe de Estado até o presente, no intuito de problematizar a reprodução dos padrões de gênero; no artigo posterior, Descolonização, feminismos e condição queer em contextos africanos, Caterina Alessandra Rea realiza um mapeamento preliminar dos estudos sobre sexualidades e teoria queer nos contextos africanos, destacando contribuições atuais produzidas por novas gerações que se preocupam em apresentar "uma versão descolonizada da dissidência sexual, que repensa o queer desde o Sul".

Questões ligadas às desigualdades de gênero no âmbito do trabalho também são abordadas neste número. No artigo Gênero, trabalho e cidadania: função igual, tratamento salarial desigual, Camila Rodrigues Neves de Almeida Lima analisa em que medida o ordenamento jurídico favorece indiretamente a discriminação das mulheres e a compensação ainda insuficiente quando se trata de discriminação positiva.

Os dois últimos artigos abordam temas que também vêm exigindo maiores reflexões. Anna Flora Brunelli é a autora do artigo Mais razão e menos emoção: o discurso de autoajuda para mulheres, no qual elabora uma crítica ao discurso de autoajuda, assinalando seu caráter melodramático, didático e impregnado de valores tradicionais que favorecem as assimetrias de gênero; Andréa Barbosa Osório Sarandy reflete sobre as críticas sexistas às mulheres que desenvolvem ações 
de proteção aos animais de rua no artigo Ecofeminismo, teorias do care e as críticas a protetoras de animais de rua, numa perspectiva que articula contribuições das teorias feministas sobre o meio ambiente às teorias do cuidado.

A seção Ponto de Vista apresenta uma entrevista com a escritora Conceição Evaristo, autora de obras literárias que têm ressaltado as interações entre gênero, classe e raça/etnia e que têm marcado a literatura dentro e fora do Brasil. A entrevista ocorreu durante o evento $13^{\circ}$ Mundos de Mulheres e $11^{\circ}$ Seminário Internacional Fazendo Gênero, realizado em Florianópolis, entre 30 de julho e 04 de agosto de 2017. Após a entrevista incluímos uma seção especial composta por nove artigos em inglês debatidos no mesmo evento, elaborados por autoras de distintos países que adotam abordagens instigantes sobre temas caros ao campo dos estudos feministas e de gênero, conforme ressalta sua organizadora - Susana Bornéo Funck - na apresentação específica desta seção que nos permite dar visibilidade à internacionalização de nossa Revista. Finalizando o número oito, há resenhas sobre obras atuais e relevantes que nos trazem mulheres negras, gênero e sexualidade na educação, transexualidade, sexualidades à deriva e crítica feminista, resenhas motivadoras para a leitura dessas recentes publicações sobre temas que interessam à área de estudos interdisciplinares na perspectiva de gênero.

Esse número busca, assim, ser mais uma vez representativo destes 26 anos da REF. O verso de Carlos Drummond de Andrade ressignificado no título de nosso editorial nos dá possibilidade de, a cada volta nas chaves de pesquisas e leituras, encontrarmos saídas.

\section{Referências}

ANDRADE, Carlos Drummond de. "À procura da poesia". In: . Rosa do Povo. 10 livros de Poesia. Rio de Janeiro: José Olympio, 1969.

BUTLER, Judith. Problemas de gênero: feminismo e subversão da identidade. Rio de Janeiro: Civilização Brasileira, 2003.

CERQUEIRA, Daniel; LIMA, Renato Sergio de; BUENO, Samira; NEME, Cristina; FERREIRA, Helder; COELHO, Danilo; ALVES, Paloma Palmieri; PINHEIRO, Mariana; ASTOLFI, Roberta e MARQUES, David (Coord.). Atlas da Violência 2018. Instituto de Pesquisa Econômica Aplicada (IPEA); Fórum Brasileiro de Segurança Pública (FBSP), 2018.

CONNELL, Robert W. Gender and Power: Society, the Person and Sexual Politics. Sidney: Allen and Unwin, 1987.

CONNELL, Robert W.; MESSERSCHMIDT, James. "Masculinidade hegemônica: repensando o conceito". Revista Estudos Feministas, v. 21, n. 1, p. 241-282, 2013. 
GOULART, Bruna Macedo. A casa sem porta. Trabalho de Conclusão da disciplina Literatura e Ensino, ministrada pela Profa Tânia Regina Oliveira Ramos. Florianópolis, Universidade Federal de Santa Catarina, 2018.

GUKOVAS, Renata; MULLER, Miriam; PEREIRA, Ana Claudia; REIMAO, Maira Emy. A Snapshot of Gender in Brazil Today: Institutions, Outcomes, and a Closer Look at Racial and Geographic Differences. Washington DC: World Bank, 2016. RAMOS, Graciliano. Infância. Rio de Janeiro: Record, 2013.

[Recebido em 10/08/2018 e aprovado em 13/08/2018]

Luzinete Simões Minella' (ib) 0000-0001-7953-7385

'Universidade Federal de Santa Catarina, Centro de Filosofia e Ciências Humanas, Departamento de Sociologia, Florianópolis, SC, Brasil

Mara Coelho de Souza Lago 2 (ib) 0000-0001-5111-8699

2Universidade Federal de Santa Catarina, Centro de Filosofia e Ciências Humanas, Departamento de Psicologia, Florianópolis, SC, Brasil

Tânia Regina de Oliveira Ramos ${ }^{3}$ ${ }^{3}$ Universidade Federal de Santa Catarina, Centro de Comunicação e Expressão, Departamento de Língua e Literatura Vernáculas, Florianópolis, SC, Brasil 